\title{
IMPLEMENTATION OF BALANCED SCORECARD IN VIETNAMESE ENTEPRISES
}

\author{
Trinh Thuy Anh \\ Ho Chi Minh City Open University
}

(Received: 20/05/2014; Revised: 28/06/2014; Accepted: 28/7/2014)

\begin{abstract}
Balanced scorecard is a highly effective method for performance measurement and strategic management in organizations and enterprises. The number of companies applying this method in Vietnam currently is not very high. For this reason, this paper aims to determine key factors for success when implementing balanced scorecard in Vietnamese enterprises. Then, it assesses the possibility for applying the method in companies who are planning to apply it. The data was collected from a survey of 6 companies who have applied balanced scorecard successfully and 19 companies who want to apply it. The data analysis result from the 6 companies who have had success with the balanced scorecard shows four major success factors, including balanced scorecard usefulness, balanced scorecard design, company human resource capacity, and balanced scorecard implementation process. Then, these factors were applied into 19 companies who have interest in implement the balanced scorecard to evaluate the ability to apply balanced scorecard. The result show that senior leaders' point of views, strategy planning and execution, performance assessment, human resource capacity, and operation management of the company could affect to balanced scorecard implementation. Therefore, business leaders need to focus on these factors in order to successfully implement balanced scorecard in Vietnamese enterprises. Qualitative analysis were applied in this study.
\end{abstract}

Keywords: balanced scorecard (BSC), strategy, enterprise

\section{Introduction}

Kaplan and Norton firstly introduced balanced scorecard (BSC) in 1992. In the beginning, BSC was used to evaluate the performance of a business (Kaplan and Norton, 1992). Then, it was considered as a tool for implementing business strategy (Kaplan and Norton, 1996). Finally, it was defined as a model to determine the consistency between company strategies and human resources, information resources and financial capital sources (Kaplan and Norton, 2001; Assiri, Zairi and Eid, 2006; Niven, 2006; Sinha, 2006; Kaplan, 2010). In recent years, many researchers in the field of management have contributed to the concept development, and many businesses in the world have adopted BSC as a management models (Geert and Edwin, 2004).

Currently in Vietnam, the majority of businesses only use financial criteria to evaluate their company performance. Using these criteria will neither allow companies to assess their potentials for future development, nor assessing their internal strengths which can help them to recognize problems related with business operation. On the other hand, performance indicators do not represent company strategies, because they lack the connections among departments in the direction to achieve common goals. Applying BSC can solve these problems. However, there 
are currently very few businesses starting to test the implementation of BSC. This study aims to identify the factors contributing to the success of implementing BSC for Vietnam companies, thereby assessing the applicability of the BSC in companies who are trying to apply.

\section{Previous studies of the implementation}

\section{of bsc}

The BSC is an effective tool to measure and manage company strategies. However, businesses usually have to deal with three major problems while implementing this model, including incompatibility between objectives and resources, conflicts of interests between company and employee, the lack of tools to control action and evaluate performance efficiency (Kaplan and Norton, 1996).

BSC design issue is one of the main reasons for the failures of big companies when they try to apply BSC. Indeed, poorly designed model dues to inapplicable measures or unable to incorporate company strategy/goal, incapable of translating strategy into action, e.g. ambiguous organizations' objectives and strategies, and imbalance between nonfinancial and financial indicators, has resulted to unpleasant outcomes when implementing BSC (Kaplan and Norton, 2001; Radnor and Lovell, 2003; Assiri, Zairi and Eid, 2006).

There are some barriers during the implementing process such as low senior level leaders' commitment, the lack of professionals or inexperienced professionals, BSC is only assessed by management, but not fully understood or implemented by employees, long development and deployment process (Kaplan and Norton, 2001; Radnor and Lovell, 2003). Some other main challenges include exceeding projected plan for time and budget, protest from employees against change, lacking of interest from senior executives, limited communication system, difficulties in strategy execution planning, lacking of consensus when proposing effective measures, and unexpected situations (Papalexandris, 2005). In addition to the attention of senior management and scorecard design, the competence of the BSC implementation team is also considered to be one of the most important factors (Assiri et. al. 2006). Therefore, top-level manager needs to fully understand, be determined, and have strong support in a long period of time for company to adapt and evolve (Chavan, 2009).

Having difficulties during strategic implementation process leads to unsuccessful implementation of BSC. Niven (2006) found four major barriers in executing strategies in organizations. They are:

- Vision barrier: only 5\% of employees understand their organizational strategies

- People barrier: only $25 \%$ of managers wish to link to strategy

- Resource barrier: $60 \%$ of organization do not tie its budget to the strategy

- Management barrier: $85 \%$ of managers at all level spend less than an hour every month to discuss about strategy.

According to Akinson (2006), there is about $70 \%$ of businesses failing in the early stage of the BSC implementation. Therefore, the implementation of the BSC must be flexible in adapting to uniquely different characteristics of the demands, markets, human resources, products, and services. Consequently, identifying feasible objectives is very crucial. In many organizations, the message about objective, strategy, or performance evaluation cannot be transferred or poorly conveyed into actions, which leads to the loss of focus and the lack of coordination to achieve organizational goals.

Nopadol Rompho (2011) conduct a study about the implementation of BSC into small and mid-size companies had discover some difficulties, including constantly changing goals and strategies, negatively affecting procedures and measures, and finally changing targets completely.

From previous studies, it is possible to say that leader perception, BSC design, human resource capacity, and the process of 
implementing BSC may affect the success implementation of BSC in businesses. Meanwhile, in order to apply BSC, companies need to focus on developing and executing the strategy, leader's point of views, business operation, and human resources capability in companies.

\section{Evaluating the success factors for the implementation of bsc in vietnamese enterprises}

Based on the success factors for implementing the BSC in companies mentioned above, the questionnaire for businesses that already applied BSC was developed. This survey consists of two parts. The first part includes 35 questions that to understand about the situation in companies when applying BSC, such as advantages and disadvantages, challenges and problems that may arise, and ways that these companies develop to handle these issues. The second part consist three questions about business information.

In six companies that are currently implementing the BSC, face-to-face interviews were conducted with top-level managers of the companies such as CEO or general manager. The survey was carried out in the period from May 2013 to August 2013. Each interview lasted for about two hours in order to analyze the factors that helped these companies to implement BSC successfully. Interviewed companies are in the list of top 500 enterprises in Vietnam, including a foreign bank that is at top level among banking system in Vietnam, a multi-national company working in information technology, an outstanding Vietnamese company in information technology, a top 5 retail business company that working in supermarket, a company in refrigerating industry, an outstanding company in medical industry. Those are medium and big enterprises.

This is explored study then the qualitative analysis was applied. Data collected from the interview were described, analyzed and catergorized as a frame that represents success factors of BSC implementation.

\section{Assessing the benefits of BSC}

All top-level managers agreed that BSC was very effective and brought many benefits to their companies. At these businesses, BSC played three important roles, including measurement system, strategic management system, and communication. Indeed, these prominent benefits have proved to be the main factors bringing high achievements for companies when implementing BSC. BSC helps increasing productivity in 5 companies; and improving the performance of departments related to finance, customer, humance resource management, administration, etc. in 6 companies. However, there are two companies that have not clearly seen the benefit of having BSC in assisting their employees to organize tasks and duties more efficiently.

\section{Designing BSC}

All respondentS said that their BSC were well designed and then connected their organizational goals to individual objectives and visibly define corporate's goals and strategies. The measures of BSC are well designed for reflecting company performance. In some businesses, the BSC consist of four perspectives: finance, customer, internal business procedure, learning and growth. However, there are still more financial than non-financial measures.

BSC design is a gradually improved process. There is a company that designs 60 measures from the begining, however during the implementing process, some of these measures are inapplicable and complicated, some measures are difficult and unquantifiable. Finally, after screening, there are only 10 essential ones. For instance, CEO of company in refrigerating industry said that "We have exclusive products and services that dominated the market, then we do not need to measure on customer perspective, that is no meaningful for us, then we decided to eliminate the customer perspective in the BSC".

\section{Human resources capability}


Employees in organizations have low understanding and support for the BSC implementation because the measurements of BSC are difficult for staff to assess. Several important factors contributing to the success of the BSC implementation include appropriate attentions from top-level managers, appropriate responsibility from mid-level managers, and qualified capability from technical support expert.

\section{Execution}

The BSC implementation process is a long and innovative process, thus business must gradually change to adapt to the current situation. Depending on certain circumstances, building BSC usually needs six months to a year. During this time, businesses need to both operate the old management system and try out the BSC. This often causes problems, and the mid-level manager is confused about the effectiveness between the two systems. The top-level manager who are interviewed said that they had to be very patient until the BSC was well implemented, and the benefits were obvious.

Since the dissemination of scorecard to individual employee faces some difficulties, some businesses choose to dispatch the information to department heads. Businesses developed scorecard project teams, having 915 members from different departments within businesses to design $\mathrm{BSC}$ and control the compliant level during the implementing process. Success comes from serious attention and meeting the requirements from the scorecard project teams. Overall plan to deploy the implementing of the BSC is a decisive factor for the success.

Implementing BSC in organizations is success because they use top-down management approach. Managers usually assess and make decision promptly during the process. Communication between the top-level managers, mid-level manager, and employees in these companies is considered to be good. Reports are made and sent periodically to the mid-level managersand that are provided to the right person, right time, right format, and the correct amounts.

\section{Evaluating the implementation of bsc in vietnamese enterprises}

Based on the factors that affect the BSC implementation process stated above, questionnaire for businesses that have not implemented the BSC was built. Part I is the main content consisting of 05 sessions with 30 questions. These questions survey for people's comments about company strategies, performance measurements, human resources, business operations, and leaders' viewpoints. The purpose is to learn about the applicability of BSC and collect suggestions for the steps and conditions to implement BSC model in businesses.

Face-to-face interviews were conducted with in nineteen companies who have not applied BSC model. Interviewees were toplevel managers who have known and planned to apply BSC. The interviews were carried out from September 2013 until February 2014. Each interview session lasted for about two hours to assess applicability of BSC in their businesses. This study aim to interview only one person represents for a company who are top-level manager such as CEO or general manager, then snow ball method was applied. The sample were multi-diversifies with 3 companies in retail industry, 3 companies in information technology, 2 companies in construction, 2 companies in transportation, 2 companies in textile industry, and other companies in communication, medical care, entertainment, book and publishing, gold and silver business, banking, tourism.

Among the total interviewed enterprises, there were $37 \%$ enterprises with more than 400 employees, $26 \%$ enterprises with 300 to 400 employees, $26 \%$ enterprises with 100 to 300 employees, and $10 \%$ enterprises with under 100 employees According to Kaplan (1996), enterprises with more than 400 employees should adopt BSC as strategic management tool. In other studies, companies with less than 200 employees may also think of using this model as well (Giannopoulos et. al., 2013). 


\section{Development and implement of strategy}

All companies have strategies; most of them are rarely changed and connected directly to the expected results. However, the connection between business performance and customer benefits is unseen or unclear. In most companies, strategy is explicitly conveyed into actions and disseminated to all staff. Though, top-level managers said that BSC execution is still facing some challenges because of capability of human resource.

\section{Business performance evaluation}

Most managers admit that their companies only evaluate performance through financial indicators. Even so, the majority of leaders realize that the apparent benefits of organizational cultures, employee knowledge, and improved manufacturing process affect their company's growth and success. As a result, some businesses begin to consider nonfinancial criteria for performance assessment.

\section{Human resource capability}

Companies rarely organize sessions to test or evaluate their employee skills annually. Although most organizations often have training and development programs, managers still see that their subordinates adapt to changes slowly, or even having difficulties in coordinating to perform some common tasks.

Most interviewees said that their employees are satisfied with their individual performance evaluations. Only a few companies have problems on this issue because the employees oppose to the BSC implementation.

There were 13 companies in which senior managers spend much time on discussing company strategy. Nonetheless, there were 7 companies in which the management team could not engage employees to company strategy. Unfortunately, this is one of main barriers for business when applying BSC.

\section{Business operation}

The operation affect to successful BSC implementation in terms of well defined business process. There were operation process in most companies; however, these process were not well developed to connect the related departments together, even the process did support to benefit customers. In general, the majority of companies said that their companies are under pressure from stakeholders to increase operation efficiency.

\section{Business leader point of views}

\section{The capability to deploy the BSC}

Top-level managers believe that it is very crucial to have uniform agreements of strategic goals among all management levels and employee knowledge about the BSC. Better tasks and duties assignment is required because BSC requires each employee to spend about two months to complete the evaluation check-list through different stages, including self-assessment, level 1 assessment, level 2 judgments, and review. Therefore, in order to successfully implement this model, employees need to be trained proficiently. As a matter of fact, this requires extensive capital and times, so it is very difficult for small-size businesses to implement.

The capability to apply BSC in small and middle enterprise

Small enterprise with under 100 employees and middleenterprises with 100300 employees have limited financial resources as well as human capital. In addition, the mid-level managers's competence and expertise in these companies are usually low and distributed unevenly. Moreover, they only pay attention to shortterm goals, which result in the unwillingness to implement the BSC.

Adjustment to the BSC so that it can be applied successfully in Vietnamese businesses

To achieve the highest outcome, Vietnamese businesses should design a simple yet practical scorecard with adequate four perspectives. In addition, business leaders must understand the importance of long-term strategy planning and execution. It is necessary that top managers need to inform this understanding to all levels within the 
organization and hold training program to enhance assessment and supervision capabilities of the management team.

\section{Conclusion}

BSC is a strategic planning and management system for aligning business operation activities with company visions and strategies.

The survey results from 6 companies that successfully applied showed BSC is effective and has brought many benefits to businesses, specifically in measurement system, strategic management, and communication. The roots to success include well-designed BSC, proper measures, high attention from top-level managers, responsible mid-level managers, and qualified technical experts. In addition, excellent planning process for developing and executing the scorecards, timely decision making from top-level managers, and good communication between all departments have greatly contributed to the success. Most of the businesses believe that the implementation of BSC is a right decision, and they are very satisfied with the model. Still, there are challenges that need to be overcome for the model to bring more values to the strategic management system, such as financial indicators are having more emphasized than non-financial criteria, and employees support and consensus need to be improved.

This study surveyed 19 companies which have not applied BSC with the purpose to assess the possibility of implementing the BSC. The analysis of the collected data shows some positive signs for BSC application. Indeed, all companies have strategies aiming to desired outcomes. These strategies are dissemminated and divided into small tasks for all employees. Top-level managers recognize the value of organizational culture, employee expertise, and improvement for better efficiency in business operation. Companies organize employee training session on a regular basis. Operation process from most companies provides good supports for creating customer values. In addition, senior managers acknowledge the importance of planning and executing long-term strategies.

However, businesses have to deal with certain challenges when adopting BSC. Company strategy does not reflect the connection between business operations and customer benefits, which lead to the difficulties in strategy execution. Most companies evaluate performance through financial creteria only, and there is no frequent testing to reassess employee capabilities and expertise. Conservative employees will hold back the application of the scorecard because they are not likely to adapt to change and even oppose to this adoption.

Thus, to successfully apply the BSC in Vietnamese enterprises, business leaders need to have long-term vision and willingness to invest in future. Current views about the model need to be changed at all management and employee levels within the company. Besides, training is required to improve assessing and supervising competence for all managers. At the same time, scorecard should have simple design but still incorporate four aspects including finance, customers, internal business processes, and learning and growth capability.

The limitation of this study is exploration with 6 companies that applied BSC successfully to discover the success factors and then apply this framework to 19 companies that going to apply BSC to evaluate the ability to implement BSC into these companies. The qualitative method was applied in this study. For futher study, a quantitative method could be applied to evaluate success factors to BSC implementation into Vietnamese enterprises. 


\section{REFERENCES}

Atkinson, H. (2006). Strategy implementation: a role for the Balanced Scorecard?. Management Decision, Vol. 44 No. 10, pp. 1441-60.

Assiri, A., Zairi, M. and Eid, R. (2006). How to profit from the BSC An implementation roadmap. Industrial Management \& Data Systems, Vol. 106 No. 7, pp. 937-952.

Chavan, M. (2009). The BSC: a new challenge. Management Development, Vol. 28 No. 5, pp. 393-406.

Eric T. (2011). Factors influencing the use of BSC. Hanken School of Economics, Helsinki.

Gautreau, A. and Keliner, B.H. (2001). Recent trends in performance management systems - the BSC approach. Management Research News, Vol. 24 No.3/4, pp. 153-6

Geert B., Nissen E. (2008). Exploring the Antecedents of Balanced Scorecard Adoption as a Performance Measurement and Strategic Management System. Nijmegen Center for Economics (NiCE), Institute for Management Research, Radboud University Nijmegen, The Netherlands, NiCE Working Paper 08-115, December 2008.

George G., Andrew H., Ehsan K. \& Stephanie C. (2013). The Use of the Balanced Scorecard in Small Companies. International Journal of Business and Management; Vol. 8, No. 14.

Geert J.M. and Edwin J. N. (2004). Performance effects of using the Balanced Scorecard: a note on the Dutch experience. Long Range Planning 37 335-349.

Nopadol R. (2011). Why the Balanced Scorecard Fails in SMEs: A Case Study. International Journal of Business and Management, Vol. 6, No. 11; November 2011.

Niven P. R. (2006). Balanced Scorecard step by step. Maximizing performance and maintaining results, John Wiley \& Sons, Inc.

Ralph F. S. (2007). Business process management and the Balanced Scorecard - Using processes as strategic drivers. John Wiley \& Sons, Inc.

Kaplan, R.S. and Norton, D.P. (1992). The Balanced Scorecard - measures that drive performance. Harvard business review, 70(1), January-February 1992, p.71-80.

Kaplan, R.S. and Norton, D.P (1996). The Balanced Scorecard - Strategy to Action. The President and Fellows of Harvard Colledge.

Kaplan, R.S. and Norton, D.P. (1996). Translating strategy into action - the Balanced Scorecard. Harvard Business School Press, Boston.

Kaplan, R. S. \& Norton, D. P. (2001). Transforming the Balanced Scorecard from Performance Measurement to Strategic Management: Part I. Accounting Horizons, 15(1), 87104.http://dx.doi.org/10.2308/acch.2001.15.1.87

Kaplan, R.S. and Norton, D.P. (2004). Measuring the strategic readiness of intangible assets. Harvard Business Review, 82(2), p.52-63.

Kaplan R. S. and Norton D. P. (2008). The execution premium: linking strategy to operations for competitive advantage. 
Kaplan R. S. (2010). Conceptual foundations of the BSC. Harvard Business SchoolPress, Boston.

Kothari, C. R. (2004). Research Methodology: Methods \& Techniques (2nd ed.). Delhi: New Age International Ltd Publishers.

Othman, R. (2008). Reflective practice enhancing the effectiveness of the BSC with scenario planning. International Journal of Productivity and Performance Management, Vol. 57 No. 3, pp. 259-266.

Papalexandris, A., Ioannou, G., Prastacos, G and Soderquist, K. E. (2005). An Integrated Methodology for Putting the Balanced Scorecard into Action. European Management Journal, Vol. 23, No. 2, pp. 214-227

Radnor, Z. và Lovell, D. (2003). Success factors for implementation of the BSC in a NHS multiagency setting. International Journal of Health Care Quality Assurance, p.99-108

Thompson R. K. and Nicholas M. J. (2008). The Aligned Balanced Scorecard: An Improved Tool for Building High Performance Organizations. Organizational Dynamics, Vol. 37, No. 4, pp. 378-393.

Sinha, A. (2006). Balanced Scorecard: A Strategic Management Tool. Vidyasagar University Journal of Commerce, 11, 71 - 81 . 